\title{
Simulation Calculation of Concrete Gravity Dam for Xiyu Reservoir During Operation Period
}

\author{
Ji Dongyu \\ Hunan Urban Construction College \\ Xiangtan, China \\ hnjdy@126.com
}

\author{
Song Chuncao \\ North China University of Water Resources and \\ Electric Power \\ Zhengzhou, China \\ 285893543@qq.com
}

\begin{abstract}
Concrete gravity dam is a common hydraulic structure, in order to have a clear understanding for concrete gravity dam in the operating process, researching stress and deformation distribution of concrete gravity dam. This paper adopts the universal finite element calculating software to simulate and calculate concrete gravity dam for Xiyu reservoir during operation period, and gives stress and displacement values on the typical section of gravity dam under the condition during operation period, and analyses calculation results, research results can provides certain theoretical basis for design and construction of concrete gravity dam. The results showed that, in the operating process, stress and deformation values of concrete gravity dam for Xiyu reservoir mainly related to water pressure and earthquake action, but the dam's stress and deformation values are smaller, the stress and deformation values can meet strength and stiffness requirements.
\end{abstract}

Keywords-Xiyu reservoir; Gravity dam; Operation period; Finite element method; Simulation analysis.

\section{INTRODUCTION}

Xiyu reservoir is located at Cuo river in Beijing pinggu county, its controlled basin area is $81.1 \mathrm{~km}^{2}$ above dam site, it is medium-sized water conservancy projects which mainly performs the functions of flood control and irrigation, and concurrently takes account of power generation. Pivotal Project is composed of dam, irrigation water diversion pipe, auxiliary dam, etc. Dam is buried stone concrete gravity dam, dam height $33.4 \mathrm{~m}$, dam crest length $279.5 \mathrm{~m}$, normal water level $30.2 \mathrm{~m}$, design water level $30.95 \mathrm{~m}$, check flood level $32.95 \mathrm{~m}$

\section{MODEL FOR GRAVITY DAM}

The concrete strength grade of concrete gravity dam for Xiyu reservoir is $\mathrm{C} 15$, elastic modulus of concrete is $22 \mathrm{GPa}$, poisson's ratio of concrete is $0.167[1]$, bulk density is $24 \mathrm{kN} / \mathrm{m}^{3}$. Foundation of dam site is quartz sandstone which is hard and almost complete[2]. Elastic modulus of rock is $15 \mathrm{GPa}$, poisson's ratio of rock is 0.3 . Seismic fortification intensity of dam is 9 degrees[3].

When establishing structural finite element calculation model for concrete gravity dam, using eight node isoparametric brick element[4-6] to simulate concrete gravity dam and rock. Based on mechanical characteristics[7-8] of gravity dam during operation period, mainly consider the following 3 kinds of calculation cases:case 1, normal water level and dead weight; case 2, design water level and tail water level and dead weight; case 3 , design water level and tail water level and dead weight and seismic action; case 4, check flood level and tail water level and dead weight.

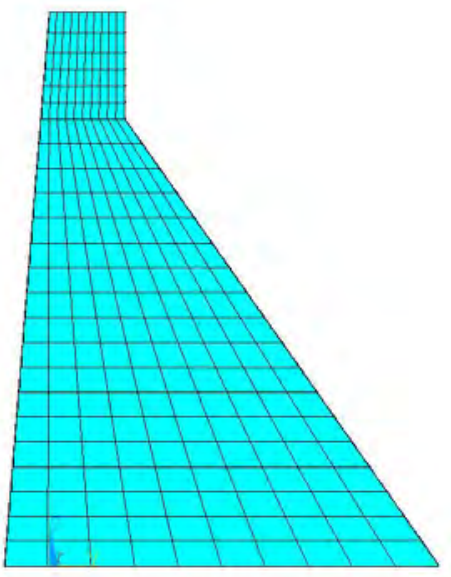

Figure 1. Element division of gravity dam section 


\section{ANALYSIS OF CALCULATION RESULTS}

\section{A Path of Analysis.}

In order to analyse distribution of stress and strain for gravity dam under different case, as can be seen from the Fig .2, this paper selects the two paths in gravity dam upstream and downstream face. On gravity dam upstream and downstream face path, this paper selects a key point every $3 \mathrm{~m}$, which were defined as key point 1 to key point 11 in turn from bottom of gravity dam to dam crest[9-10].

\section{B Stress Analysis.}

Stress value of key points for gravity dam section under different case show in the table 1 . As can be seen from the table 1, stress value of key points on gravity dam upstream and downstream face path under different case is compressive stress basically. only under case 3 , small tensile stress appears at the point of intersection of gravity dam upstream face and foundation, the value of which is $0.01 \mathrm{MPa}$, this is mainly the result of seismic action. Under different case, compressive stress on gravity dam upstream face is little less than compressive stress on gravity dam downstream face, compressive stress at key points decreases from dam crest to bottom of gravity dam, this is mainly caused by water pressure.

TABLE I. STRESS VALUE OF KEY POINTS FOR GRAVITY DAM SECTION UNDER DIFFERENT CASE (MPA)

\begin{tabular}{|c|c|c|c|c|c|c|c|c|c|c|c|c|}
\hline \multicolumn{2}{|c|}{ Location } & 1 & 2 & 3 & 4 & 5 & 6 & 7 & 8 & 9 & 10 & 11 \\
\hline \multirow{2}{*}{ Case 1} & $\begin{array}{l}\text { Upstream } \\
\text { face }\end{array}$ & -0.26 & -0.46 & -0.45 & -0.39 & -0.34 & -0.31 & -0.27 & -0.24 & -0.19 & -0.13 & -0.08 \\
\hline & $\begin{array}{l}\text { Downstream } \\
\text { face }\end{array}$ & -0.64 & -0.51 & -0.43 & -0.38 & -0.31 & -0.25 & -0.18 & -0.14 & -0.10 & -0.20 & -0.07 \\
\hline \multirow{2}{*}{ Case 2} & $\begin{array}{l}\text { Upstream } \\
\text { face }\end{array}$ & 0.25 & -0.46 & -0.44 & -0.38 & -0.33 & -0.29 & -0.26 & -0.23 & -0.18 & 0.13 & -0.07 \\
\hline & $\begin{array}{l}\text { Downstream } \\
\text { face }\end{array}$ & -0.65 & -0.52 & -0.44 & -0.38 & -0.32 & -0.25 & -0.19 & -0.15 & -0.11 & -0.21 & -0.08 \\
\hline \multirow{2}{*}{ Case 3} & $\begin{array}{l}\text { Upstream } \\
\text { face }\end{array}$ & 0.01 & -0.31 & -0.34 & -0.29 & -0.25 & -0.22 & -0.19 & -0.16 & -0.12 & -0.08 & -0.05 \\
\hline & $\begin{array}{l}\text { Downstream } \\
\text { face }\end{array}$ & -0.78 & -0.62 & -0.52 & -0.46 & -0.40 & -0.32 & -0.26 & -0.20 & -0.16 & -0.27 & -0.10 \\
\hline \multirow[b]{2}{*}{ Case 4} & Upstream face & -0.24 & -0.44 & -0.42 & -0.36 & -0.32 & -0.27 & -0.24 & -0.22 & -0.16 & -0.11 & -0.06 \\
\hline & $\begin{array}{c}\text { Downstream } \\
\text { face }\end{array}$ & -0.67 & -0.53 & -0.46 & -0.40 & -0.34 & -0.27 & -0.21 & -0.17 & -0.12 & -0.22 & -0.09 \\
\hline
\end{tabular}

Contour map of vertical stress for gravity dam under case 2 and case 3 shows in the Fig .2 and Fig .3. As can be seen from Fig .2 and Fig. 3, stress-focus phenomenon appears at dam heel and toe under case 2 and case 3, the whole dam body is compressive stress basically, compressive stress at the bottom of gravity dam is larger and decreases with the increase of elevation. Under case 3 , due to the influence of seismic action, compressive stress at dam heel decreases sharp, and maximum compressive stress appears at dam toe.
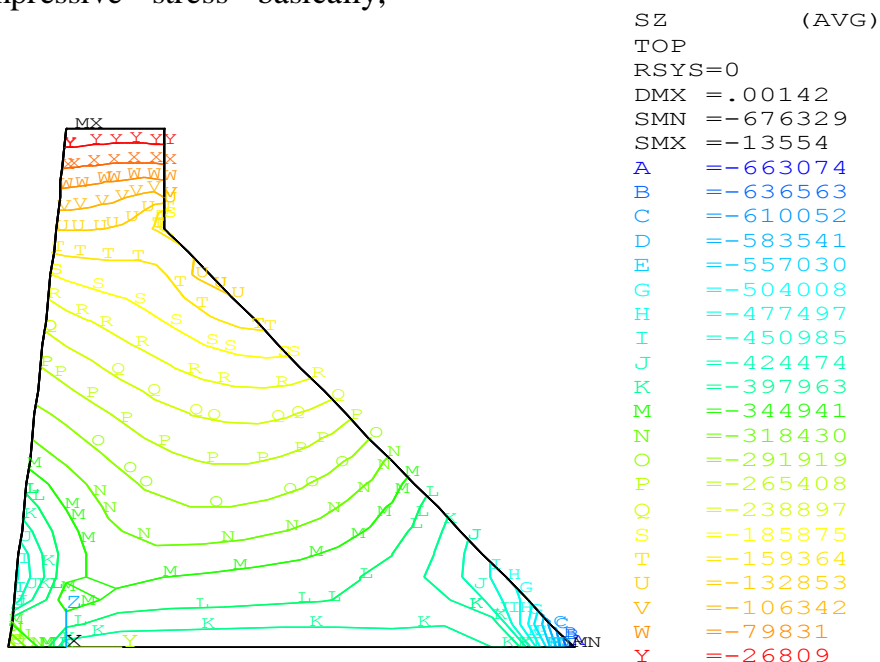

Figure 2. Contour map of vertical stress for gravity 


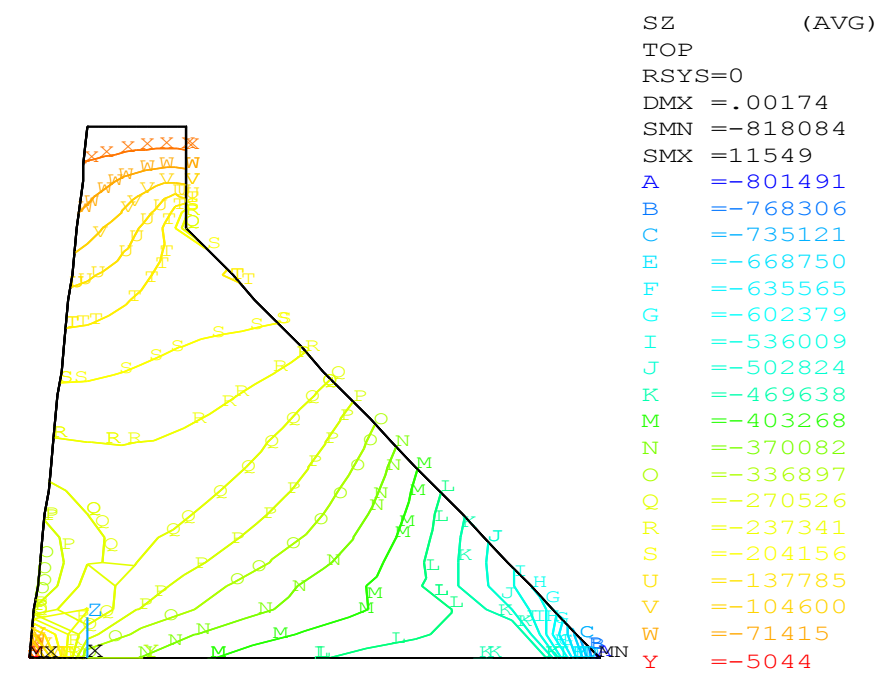

Figure 3. Contour map of vertical stress for gravity dam under case $2(\mathrm{~Pa})$ gravity dam under case $3(\mathrm{~Pa})$

Horizontal displacement value of key points for gravity dam section upstream face under different case show in the table 2. As can be seen from the table 2, horizontal displacement value of key points for gravity dam section upstream face under different case is small and increases with the increase of water level.
Horizontal displacement value for gravity dam increases from bottom of gravity dam to dam crest, this is mainly caused by water pressure. Under case 3, horizontal displacement value for gravity dam is larger, this is due to case 3 considers the earthquake action.

TABLE II HORIZONTAL DISPLACEMENT VALUE OF KEY POINTS FOR GRAVITY DAM SECTION UPSTREAM FACE UNDER DIFFERENT CASE (MM)

\begin{tabular}{|c|c|c|c|c|c|c|c|c|c|c|c|}
\hline Location & 1 & 2 & 3 & 4 & 5 & 6 & 7 & 8 & 9 & 10 & 11 \\
\hline Case 1 & 0.237 & 0.351 & 0.396 & 0.419 & 0.438 & 0.447 & 0.451 & 0.459 & 0.460 & 0.451 & 0.499 \\
\hline Case 2 & 0.247 & 0.359 & 0.403 & 0.428 & 0.444 & 0.455 & 0.463 & 0.467 & 0.466 & 0.462 & 0.458 \\
\hline Case 3 & 0.323 & 0.483 & 0.569 & 0.637 & 0.697 & 0.755 & 0.814 & 0.873 & 0.932 & 0.996 & 1.066 \\
\hline Case 4 & 0.258 & 0.371 & 0.417 & 0.441 & 0.451 & 0.468 & 0.472 & 0.479 & 0.477 & 0.475 & 0.474 \\
\hline
\end{tabular}

Contour map of horizontal displacement for gravity dam under case 2 and case 3 shows in the Fig .4 and Fig .5. As can be seen from Fig .4 and Fig .5, maximum horizontal displacement value appears at dam crest, horizontal displacement value under case 3 is $1.135 \mathrm{~mm}$ and lager than horizontal displacement value under case 2 . 


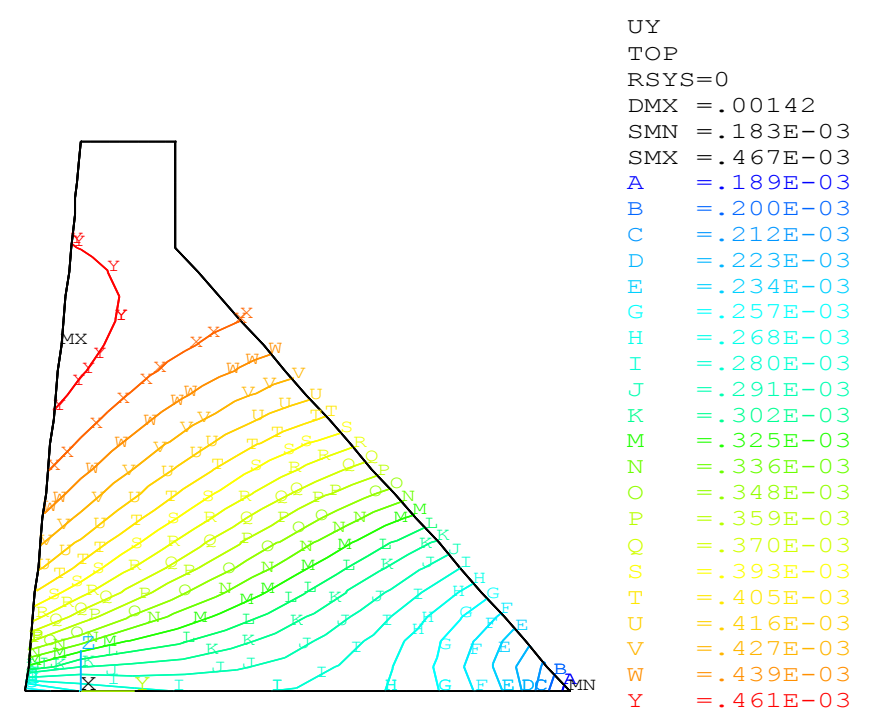

Figure 4. Contour map of horizontal displacement for gravity dam under case 2 (m)

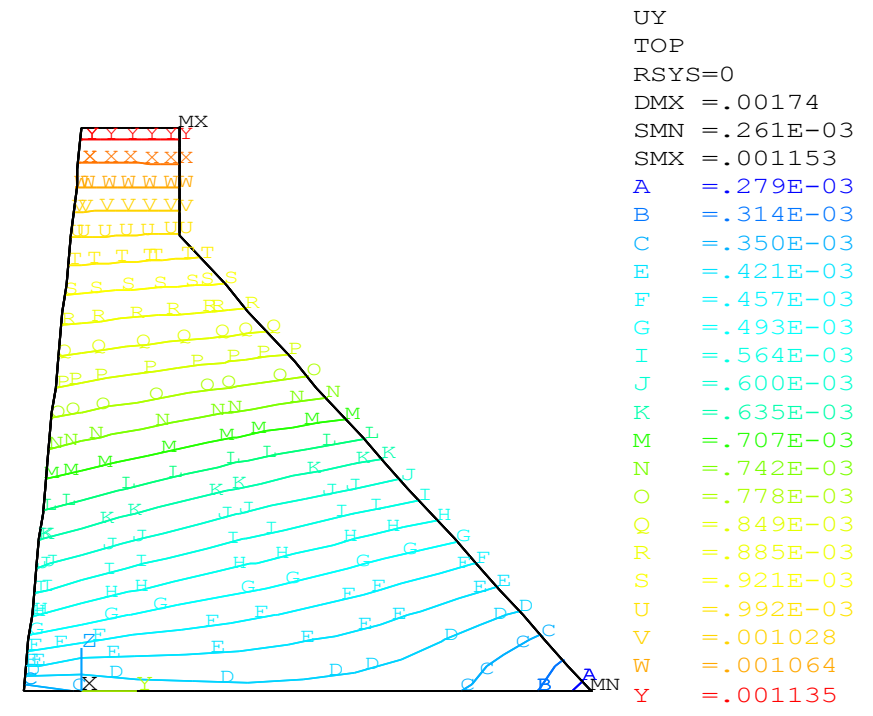

Figure 5. Contour map of horizontal displacement for gravity dam under case 3 (m)

\section{CONCLUSION}

In conclusion, during operation period, stress and displacement value of concrete gravity dam for Xiyu reservoir are mainly related to water pressure and earthquake action, stress and displacement value of dam body is small and can meet the requirements of strength and stiffness.

\section{REFERENCES}

[1] SL191-2008. Design Code for Hydraulic Concrete Structure[S]. China Water Conservancy and Hydropower Press, 2008.

[2] Mingrong Shen, Jianfeng Chen. Rock mechanics [M]. Tongji University Press, 2006.

[3] H. Shariatmadar, A. Mirhaj. Dam-reservoir-foundatJon interaction effects on the modal characteristic of concrete gravity dams [J]. Structural engineering and mechanics, 2011, 38(1): 65-79.

[4] Xucheng Wang. Finite Element Method [M]. Tsinghua University Press, 2003.
[5] Bofang Zhu. Finite Element Method Principle and Application [M]. China Water Conservancy and Hydropower Press, 1998.

[6] Yuan Chen,Gengxin Yang,Jianhua Dong et al. Anti-sliding stability of a gravity dam on complicated foundation with multiple structural planes [J]. International Journal of Rock Mechanics and Mining Sciences,2012,55:151-156.

[7] Shanding Ma, Ruze Wang. Hydropower Station Structures (The Second Edition) $[\mathrm{M}]$. China Water Conservancy and Hydropower Press, 1996.

[8] B. Phansri,S. Charoenwongmit,P. Warnitchai et al. Numerica simulation of shaking table test on concrete gravity dam using plastic damage model [J]. Structural engineering and mechanics, 2010,36(4):481-497.

[9] I. Karimi,N. Khaji,M.T. Ahmadi et al. System identification of concrete gravity dams using artificial neural networks based on a hybrid finite element-boundary element approach [J]. Engineering structures,2010,32(11):3583-3591.

[10] Hamidreza Arabshahi,Vahid Lotfi. Earthquake Response Of Concrete Gravity Dams Including Dam-foundation Interface Nonlinearities [J]. Engineering Structures, 2008, 30(11):3065-3073. 